\title{
Condiloma acuminado en cavidad oral: revisión de la literatura
}

\section{Condyloma acuminatum in the oral cavity: review of the literature}

\author{
Libertad Marien León Véjar, ${ }^{*}$ Mario Nava Villalba, ${ }^{\ddagger}$ José Sergio Zepeda Nuño, ${ }^{\ddagger}$ \\ Diana Elizabeth Aguirre Cortés, ${ }^{\S}$ Cecilia Robles Gómez, ${ }^{\Uparrow}$ Miguel Padilla Rosas $₫$
}

\section{RESUMEN}

El condiloma acuminado (CA) es una lesión y una enfermedad de transmisión sexual que se da con mucha frecuencia. Ésta es transmitida por el virus del papiloma humano (VPH) subtipos 6 y 11; se caracteriza por su apariencia exofítica papilomatosa semejante a una coliflor. Se observa con mayor frecuencia en región anogenital; sin embargo, también se puede encontrar en mucosa oral. El diagnóstico definitivo es clínico-patológico, se realiza mediante el estudio histopatológico de la lesión y los antecedentes clínicos. El tratamiento es la remoción quirúrgica de la lesión por medio de bisturí, láser, crioterapia, entre otras. Aunque en algunos casos el uso de inmunomoduladores, como el imiquimod, es el tratamiento de elección.

Palabras clave: Condiloma acuminado, virus del papiloma humano, lesiones verrucosas.

\section{INTRODUCCIÓN}

El condiloma acuminado (CA) se define en la literatura como una de las enfermedades de transmisión sexual más frecuentes, se da por infección del virus de papiloma humano (VPH) subtipos 6 y 11, y en algunas fuentes incluye el 42. ${ }^{1,2}$ Clínicamente es una lesión de apariencia

\section{ABSTRACT}

Condyloma acuminatum (CA) is a lesion and a sexually transmitted disease transmitted by the human papillomavirus (HPV) subtypes 6 and 11 characterized by its exophytic papillomatous cauliflower-like appearance. It is most frequently observed in the anogenital region, however, it can also be found in the oral mucosa. The definitive diagnosis is clinicopathologic and is made by histopathologic study of the lesion and clinical history. The treatment is surgical removal of the lesion by means of scalpel, laser, cryotherapy, among others. Although in some cases the use of immunomodulators, such as imiquimod, is the treatment of choice.

Keywords: Condyloma acuminatum, human papillomavirus, verrucous lesions.

nodular, superficie papilomatosa, blanda, puede ser sésil y/o pediculada que asemeja una coliflor. ${ }^{1,3}$

\section{ETIOPATOLOGÍA}

El origen del CA se da por la infección por VPH, subtipos 6 y 11 , que infecta la piel y membranas mucosas durante la

\footnotetext{
Pasante de la Licenciatura en Cirujano Dentista. Departamento de Clínicas Odontológicas Integrales.

₹ Profesor del Departamento de Microbiología y Patología.

Estudiante de la Maestría en Patología y Medicina Bucal.

ף Profesor del Departamento de Clínicas Odontológicas Integrales.
}

Centro Universitario de Ciencias de la Salud de la Universidad de Guadalajara. México. 
actividad sexual, por autoinoculación o al tener contacto directo con objetos contaminados. El virus se abre paso a través de microtraumas, de la piel y/o mucosa anogenital y oral, llegando a las células de la capa basal, siendo éstas las responsables de la renovación del epitelio. El ADN viral se replica en el núcleo de las células infectadas, dando lugar así a la lesión. Tiene un tiempo de incubación de uno a tres meses. ${ }^{4}$ También existe la posibilidad de coinfección por subtipos de alto riesgo de transformación maligna, 16 y 18.5,6 Los VPH pertenecen a la familia Papoviridae, son de tamaño pequeño y tienen una cápside con una molécula de ADN circular bicatenario única. ${ }^{2}$

\section{CARACTERÍSTICAS CLÍNICAS}

El CA es una lesión blanda, rosada o con áreas ligeramente blanquecina, con proyecciones de superficie roma, nodular, exofítica, no dolorosa, bien delimitada de base sésil o pediculada. Puede desarrollarse en mucosa y piel de la región anogenital y en mucosa oral. Puede medir de 1 hasta $3 \mathrm{~cm}$ de diámetro. Los condilomas pueden ser únicos o múltiples, tienden a agruparse entre ellos. ${ }^{7,8}$
Se observan con mayor frecuencia en mucosa de labios, frenillo lingual, dorso de lengua y comisuras (Figura 1).9-11

\section{EPIDEMIOLOGÍA}

Afecta a hombres y mujeres por igual, se dice que afecta a $60 \%$ de las personas sexualmente activas. Sin embargo, a pesar de ser una de las enfermedades de transmisión sexual (ETS) más frecuentes, las manifestaciones tanto orales como anogenitales tienen subregistro, debido a que no es una entidad de reporte epidemiológico obligado, no existen datos precisos, ya que se les da preferencia a los subtipos de VPH con riesgo de malignización. En EUA son diagnosticados cada año entre 500,000 y un millón de nuevos casos de condiloma cada año, lo cual representa $1 \%$ de la población sexualmente activa. ${ }^{2}$

Un estudio realizado en Perú, cuyo objetivo fue conocer las características demográficas del CA, donde se encontró una predominancia en el sexo masculino; no obstante, llegaron a la conclusión de que las mujeres podrían equiparar en la frecuencia, ya que se cree

Figura 1:

Manifestaciones en mucosa oral. Se observan fotografías de lesiones verrugosas, pediculadas de superficie papilomatosa, en diferentes áreas de la mucosa bucal, cabe mencionar que son de pacientes diferentes y en todos ellos el diagnóstico histológico fue compatible con condiloma acuminado.
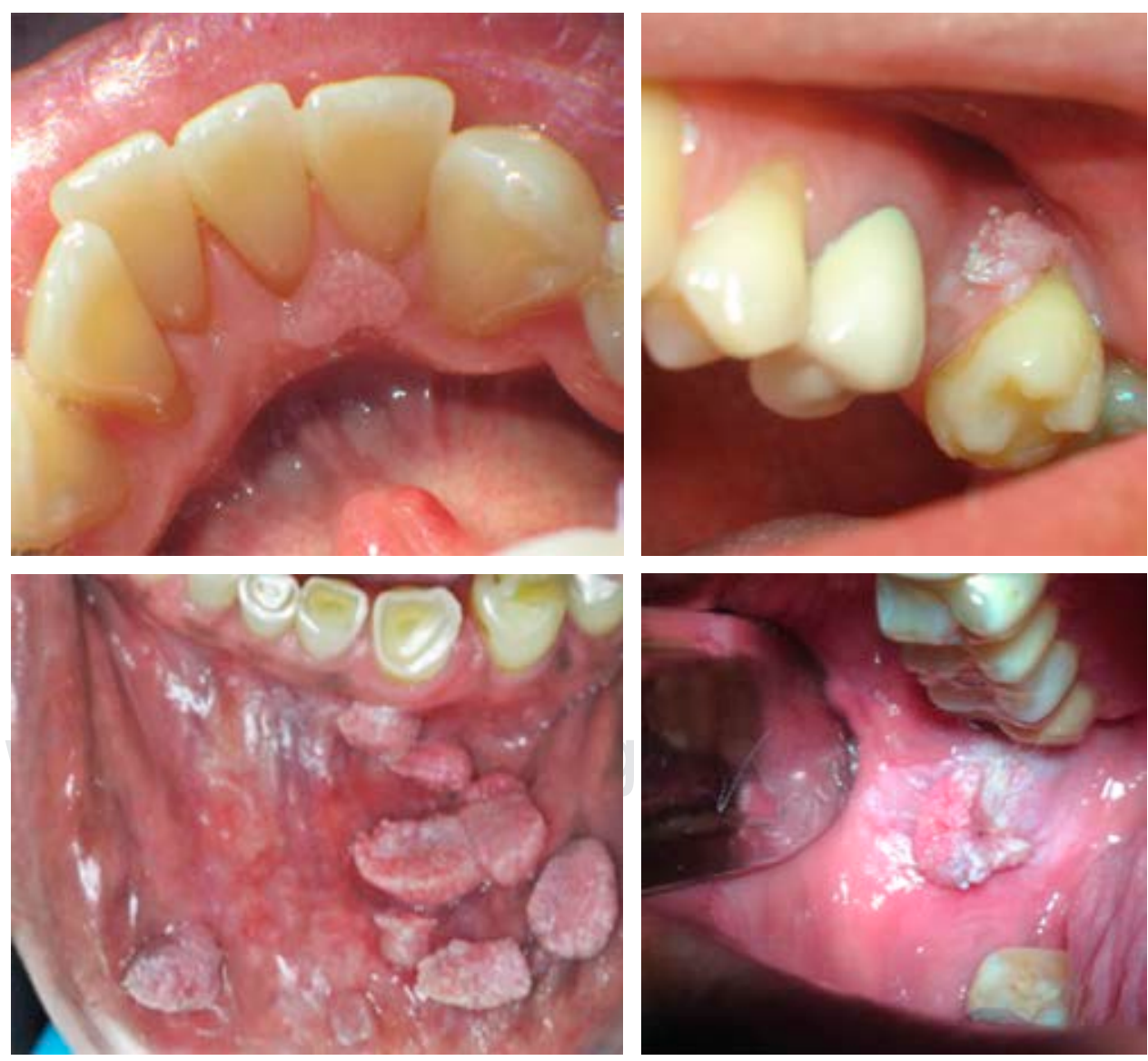


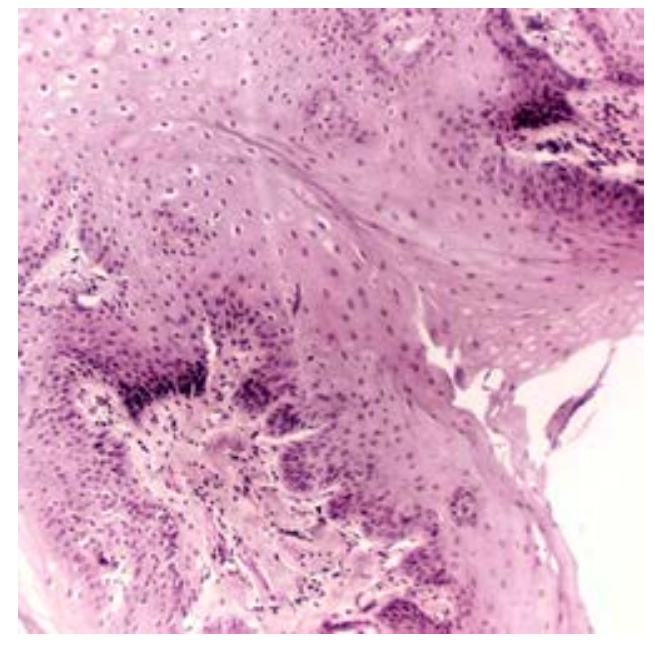

Figura 2: Histopatología en mucosa oral. En este corte histopatológico con un acercamiento $10 x$ teñido con hematoxilina y eosina se observa un fragmento de epitelio de la mucosa bucal, donde se identifica un epitelio acantótico, con clavos epiteliales globosos y múltiples coilocitos.

que existe subregistro por lesiones en genitales internos no visibles. También se encontró predominancia en adolescentes y adultos jóvenes con prácticas sexuales sin protección y tendencia a la promiscuidad, grado de escolaridad preuniversitario y con ocupación de empleados. ${ }^{12}$

La presencia de CA en población pediátrica es una señal de alerta para sospechar de abuso sexual, aunque se dice que existe la posibilidad de transmisión vertical. En niños, el género más afectado es el femenino 1.5 a 2 veces más que el masculino. 3,13

\section{HISTOPATOLOGÍA}

El CA se observa como una proliferación benigna del epitelio escamoso estratificado, con presencia de acantosis, moderada queratosis, proyecciones papilares de la superficie en el estrato espinoso, más anchas y redondeadas en comparación a papiloma escamoso y verruga vulgar, con la presencia característica de coilocitos. Se observa también epitelio maduro y bien diferenciado con núcleos de tejido conectivo delgado que dan soporte a las proyecciones papilares, también se pueden observar de manera frecuente criptas llenas de queratina entre las proyecciones. Los coilocitos no son tan prominentes en lesiones de la mucosa oral en comparación con las lesiones anogenitales, lo cual puede dificultar la distinción con el diferencial de papiloma escamoso (Figuras 2 y 3). $1,7,14$

\section{DIAGNÓSTICO}

El diagnóstico final de CA se realiza por medio del ejercicio clínico-patológico, en las que incluye la apariencia clínica y del estudio histopatológico de una biopsia escisional, de forma que al ser compatible con la descripción histopatológica previamente descrita se da el diagnóstico. Cabe mencionar que la presencia de coilocitos únicamente determina la presencia del VPH y no los subtipos, no siempre se tiene la seguridad en el diagnóstico histopatológico, por lo que en algunos casos se sugieren exámenes complementarios. ${ }^{15}$

Exámenes complementarios. Inmunohistoquímica, hibridación in situ y/o reacción en cadena de la polimerasa $(\mathrm{PCR})$ para determinar el subtipo viral. ${ }^{5,16}$

\section{PRONÓSTICO}

Al ser una lesión benigna el pronóstico es bueno, ya que en boca no se ha observado la malignización por coinfección de VPH 16 y/o 18, sin embargo, la lesión debe ser removida al ser altamente contagiosa y existir el riesgo de propagación en otras personas o en la misma persona por autoinoculación. También es una lesión con alto grado de recidivas, ya que el tejido circunvecino de apariencia normal puede albergar partículas virales y así ser la fuente de las recidivas. Además, debe estudiarse si el paciente no tiene alguna otra enfermedad de transmisión sexual concomitante como el virus de inmunodeficiencia humana $(\mathrm{VIH})$. El CA en pacientes con $\mathrm{VIH}$ que reciben

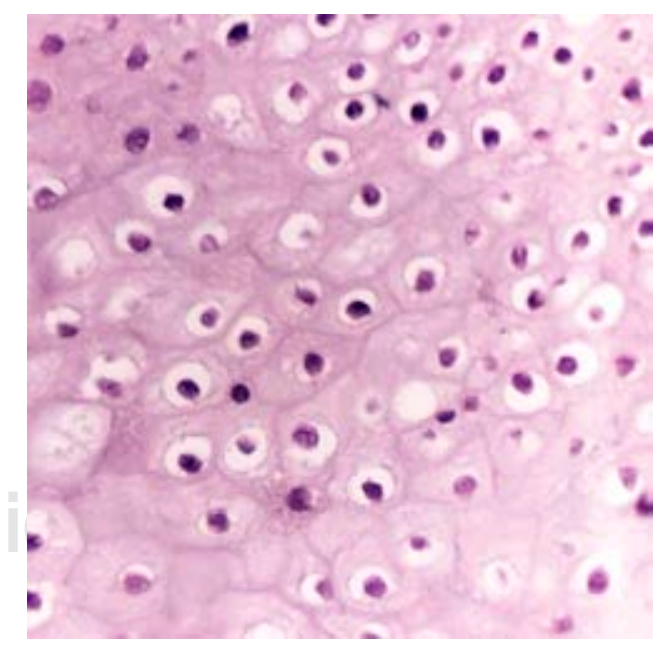

Figura 3: Presencia de coilocitos. En este acercamiento $40 x$ se observan los coilocitos, son queratinocitos con un halo blanquecino alrededor del núcleo que hacen que se sospeche de infección por virus del papiloma humano. 
tratamiento de terapia antirretroviral de gran actividad tiene la posibilidad de transformación maligna, deformación e impacto en la función. ${ }^{6,17}$

\section{TRATAMIENTO}

Las opciones de tratamiento son múltiples, como la biopsia escisional por escisión quirúrgica, criocirugía o láser, ablación láser, crioterapia o electrodesecación.

En pacientes con VPH, que además presentan una infección por VIH y tratamiento tipo terapia antirretroviral de gran actividad (TARGA), se ha encontrado la prevalencia del CA con apariencia súbita, de curso rápido e incontrolado, además de que no responde a los tratamientos convencionales, por lo que se reporta el uso de imiquimod al 5\% en mucosa oral. El imiquimod actúa estimulando citocinas como interferón $\alpha$ IL-1, IL-6, TNF- $\alpha$, entre otras. El imiquimod al $5 \%$ se utiliza en un esquema de tres días a la semana por las noches durante ocho semanas, obteniendo así una reducción significativa y progresiva de las lesiones, evitando así el daño estético que podría causar la remoción quirúrgica y reduciendo de manera importante las recidivas. ${ }^{6,17}$

\section{CONCLUSIÓN}

$\mathrm{Al}$ realizar esta revisión concluimos que es necesario hacer hincapié en el reporte de estas lesiones, ya que al ser una de las ETS más frecuentes, la existencia de un subregistro nos hace inferir que hay muchas más personas afectadas de lo que realmente dice la literatura. Además, es importante considerar esta entidad en distintos diferenciales, ya que en la boca, por las características clínicas e histopatológicas, puede confundirse fácilmente con otras lesiones y de aquí también podría originarse el subregistro. Encontramos de suma importancia esto, ya que, como se menciona, puede existir coinfección con otros serotipos de VPH y poner en riesgo la vida de nuestros pacientes, por lo que debemos realizar tanto un estudio exhaustivo del historial clínico del paciente como de las lesiones, para prevenir en la medida de lo posible recidivas y complicaciones mayores.

\section{REFERENCIAS}

1. Cháirez Atienzo P, Vega Memíje ME, Zambrano Galván G, García Calderón AG, Maya García IA, Cuevas González JC. Presencia del virus papiloma humano en la cavidad oral: revisión y actualización de la literatura. Int J Odontostomat. 2015; 9 (2): 233-238.

2. Nieto Jiménez Al. Condiloma acuminado. Situación actual. Bionaura. 2018; 3 (2): 619-625.

3. López SAL, Basurto FJC, Salazar MR. VPH en cavidad oral: condiloma. Rev Tame. 2019; 7 (21): 838-841.

4. Arenas Guzmán R. Dermatología. Atlas, diagnóstico y tratamiento. 6a ed. México: McGraw-Hill; 2015.

5. Medina ML, Medina MG, Merino LA. Consideraciones actuales sobre la presencia de papilomavirus humano en la cavidad oral. Av Odontoestomatol. 2010; 26 (2): 71-80.

6. Curi DS, Leite-Ribeiro PM, Torregrossa VR, Vieira VC, Sarmento VA. Efficacy of imidazolquinoline on treatment of condyloma acuminatum of the buccal mucosa. Spec Care Dentist. 2017; 37 (1): 51-54.

7. Neville B, Damm DD, Allen C, Chi A. Oral and maxillofacial pathology. St. Louis, Missouri: Elsevier; 2016.

8. Pérez-Salcedo L, Bascones Martínez A. Tumores benignos de la mucosa oral. Av Odontoestomatol. 2010; 26 (1): 11-18.

9. Fernández López C, Morales Angulo C. Lesiones otorrinolaringológicas secundarias al sexo oral. Acta Otorrinolaringol Esp. 2017; 68 (3): 169-180.

10. Rozas-Llerena R, Sebastian-Ayala R. Condiloma viral en lengua: presentación de un caso clínico y revisión bibliográfica. Rev Fac Med. 2019; 19 (1): 105-107.

11. Delgado QEG, Sandoval MMA, Guzmán PJE, Valdivia LA. Condiloma viral en lengua: presentación de un caso clínico y revisión bibliográfica. Arch Med Fam. 2011; 13 (2): 74-76.

12. Alfonso-Trujillo I, López-Saura PA, Cazarez-Pérez D, TamargoBarbeito TO, Hernández-Pavón Y, Puig-Pérez M. Caracterización clínica, epidemiológica y terapéutica de pacientes con condiloma acuminado. Dermatol Peru. 2014; 24 (2): 80-88.

13. Percinoto AC, Danelon M, Crivelini MM, Cunha RF, Percinoto C. Condyloma acuminata in the tongue and palate of a sexually abused child: a case report. BMC Res Notes. 2014; 7: 467.

14. Henley JD, Summerlin DJ, Tomich CE. Condyloma acuminatum and condyloma-like lesions of the oral cavity: a study of 11 cases with an intraductal component. Histopathology. 2004; 44 (3): 216-221.

15. Holmstrup P, Plemons J, Meyle J. Non-plaque-induced gingival diseases. J Periodontol. 2018; 89 Suppl 1: S28-S45.

16. Carmona-Lorduy M, Porto-Puerta I, Lanfranch H, Medina-Carmona W, Werner L, Maturana S. Manifestaciones bucales de enfermedades de transmisión sexual identificadas en tres servicios de estomatología en Sur América. Univ Salud. 2018; 20 (1): 82-88.

17. Soto RR, Pérez AJ, Araya SC. Manejo quirúrgico de múltiples condilomas de la mucosa oral en paciente bajo terapia antirretroviral de gran actividad. Int J Odontostomat. 2018; 12 (1): 93-98.

\section{Correspondencia:}

Dr. Miguel Padilla Rosas

E-mail: miguelpadilla_rosas@hotmail.com 